\title{
Aspiration and ethanol sclerotherapy to treat recurrent ovarian endometriomas prior to in vitro fertilization - a pilot study
}

\author{
Aspiração e alcoolização de endometriomas ovarianos recorrentes prévios ao tratamento de \\ fertilização in vitro - estudo piloto
}

Gustavo Mendonça André ${ }^{1}$, Fábia Lima Vilarino ${ }^{1}$, Denise Maria Christofolini ${ }^{1}$, Bianca Bianco ${ }^{1}$, Caio Parente Barbosa ${ }^{1}$

\begin{abstract}
Objective: To describe the evolution of controlled ovarian hyperstimulation in women with recurrent ovarian endometriomas treated with sclerotherapy. Methods: Twenty-one patients with a laparoscopic diagnosis of stage III or IV endometriosis who had an endometrioma larger than $3 \mathrm{~cm}$ before ovarian hyperstimulation for in vitro fertilization were included in the study. After using a $\mathrm{GnRH}$ agonist analog for at least 20 days, the cysts were punctured using ultrasound guidance and subsequent ethanol sclerotherapy was performed. Then, the patients were stimulated with 100 or $200 \mathrm{U} /$ day of recombinant follicle stimulating hormone, varying the dose according to the patient's age or history of a previous unilateral oophorectomy. Results: The ovarian cysts had an average diameter of $4.7 \pm 1.4$ $\mathrm{cm}$ and did not recur after aspiration during the ovulation induction. Oocyte extraction occurred after 11 days of hyperstimulation, with $3.95 \pm 3.30$ oocytes obtained per cycle, on average. Embryo transfer occurred in $71.4 \%(15 / 21)$ of patients, and the pregnancy rate after transfer was 20\% (3/15). Conclusion: Aspiration followed by ethanol sclerotherapy prior to in vitro fertilization can be an option for patients who desire a pregnancy and have recurrent endometriomas.
\end{abstract}

Keywords: In vitro fertilization; Endometriosis; Sclerotherapy; Reproductive techniques; Infertility

\section{RESUMO}

Objetivo: Relatar a evolução da hiperestimulação ovariana controlada em mulheres com endometriomas ovarianos recorrentes tratados com escleroterapia. Métodos: Foram estudadas 21 pacientes acompanhadas no ambulatório de reprodução humana com indicação de fertilização in vitro e diagnóstico laparoscópico de endometriose III ou IV que apresentavam endometrioma recidivado maior que $3 \mathrm{~cm}$ após a cirurgia. Foi realizado bloqueio prévio com análogo agonista de GnRH por pelo menos 20 dias, e os cistos foram submetidos à punção guiada por ultrassonografia e alcoolização subsequente. As pacientes foram estimuladas com 100 ou 200U/dia de hormônio folículo estimulante recombinante, com a dose variando de acordo com a idade ou ooforectomia unilateral prévia. Resultados: Os cistos ovarianos aspirados tinham em média $4,7 \pm 1,4 \mathrm{~cm}$ e em nenhum caso a imagem se refez durante a indução da ovulação. A captação oocitária ocorreu, em média, após 11 dias de indução com 3,95 $\pm 3,30$ oócitos por ciclo. Houve transferência embrionária em 71,4\% (15/21) das pacientes, e a taxa de gravidez por transferência foi de $20 \%$ (3/15). Conclusão: A aspiração seguida da alcoolização previamente ao tratamento de fertilização in vitro pode ser uma opção para as pacientes com endometriomas recidivados e desejo reprodutivo.

Descritores: Fertilização in vitro; Endometriose; Escleroterapia; Técnicas reprodutivas; Infertilidade

\section{INTRODUCTION}

Ovarian endometriomas are considered an invagination of endometriotic tissue and are frequently treated with surgery. Studies have suggested that endometriomas may affect an ovary's response to stimulation, oocyte retrieval, and implantation ${ }^{(1)}$. Several studies have shown that women with endometriosis have a lower ovarian response to gonadotropins ${ }^{(2,3)}$. In a study performed in 2000 , the authors found that women with endometriosis required more ampoules of gonadotropins per cycle compared to a control group of women with infertility related to their fallopian tubes ${ }^{(2)}$. A prior ovarian resection may be the reason for the reduced ovarian response. Studies have also shown that the decreased response to gonadotropin stimulation is possibly due to the negative biochemical influence of the endometrioma, while other studies emphasize the decreased number of retrieved oocytes in patients with endometriomas ${ }^{(4,5)}$.

The diagnosis of endometrioma has traditionally been made by visual inspection of the pelvis via

\footnotetext{
Study carried out at the Center for Human and Genetic Reproduction, Department of Gynecology and Obstetrics, Faculdade de Medicina do ABC - FMABC, Santo André (SP), Brazil.

'Faculdade de Medicina do ABC - FMABC, Santo André (SP), Brazil.

Correspondig author: Caio Parente Barbosa - Avenida Príncipe de Gales, 821 - CEP 09060-650 - Santo André (SP), Brazil - Tel/Fax: 1144387299 - E-mail: caiopb@uol.com.br

Received on: Apr 26, 2011 - Accepted on: Nov 1, 2011

Conflicts of interest: none
} 
laparoscopy or laparotomy. The laparoscopic diagnosis usually requires general anesthetics, and the procedure is associated with a $3 \%$-rate of minor complications (nausea, vomiting, and shoulder pain) and a $0.5 \%$-rate of severe complications (such as intestinal perforation). Considering these potential risks, there is strong interest in non-invasive techniques, such as ultrasonography, to detect endometriosis ${ }^{(6)}$.

Considering their echogenic characteristics, endometriomas may be easily distinguished from other ovarian cysts. The sensitivity and specificity in transvaginal ultrasound to detect endometriomas varies from $84 \%$ to $100 \%$ and from $90 \%$ to $100 \%$, respectively ${ }^{(4)}$.

In general, the treatment of choice for these cysts is surgery: a cystectomy or fenestration with laparoscopy; the recurrence rate is $20 \%$ in 5 years $^{(6)}$. However, after surgical treatment, there is a reduced response to ovarian stimuli and a decrease in the number of retrieved oocytes ${ }^{(5)}$, which suggests that more conservative treatment should be used in patients who desire pregnancy. It is important to stress that the management of endometriomas is one of the most controversial topics in the literature, ranging from groups who opt for an expectant approach to those who always tend to perform a cystectomy.

Dicker et al. ${ }^{(7)}$ and Aboulghar et al. ${ }^{(8)}$ described a technique for aspirating endometriomas using ultrasound guidance. Another related technique was the use of tetracycline as an agent for sclerotherapy in ovarian cysts during surgery and then as treatment prior to the induction of ovulation with assisted reproduction ${ }^{(9)}$. Mesogitis et al. ${ }^{(10)}$ reported that aspiration, followed by the injection of methotrexate, had an endometrioma recurrence rate of 5-20\%. Noma and Yoshida ${ }^{(11)}$ performed cyst reduction while preserving the ovarian tissue and folliculogenesis using sclerotherapy with ethanol and observed a recurrence of $14.9 \%$. The incidence of recurrence ranges from 9.1 to $66.7 \%$, according to various studies. Hiesh et al. ${ }^{(12)}$ demonstrated that the rate of recurrence was $13.3 \%$ when the ethanol was not aspirated versus $32.1 \%$ when it was.

\section{OBJECTIVE}

To describe the evolution of ovarian hyperstimulation for assisted reproduction and to report the results of ovarian aspiration and ethanol application in recurring ovarian endometriomas.

\section{METHODS}

This was a prospective pilot study that included 21 patients who were recruited at the Center Human and Genetic Reproduction at Faculdade de Medicina do
$A B C$ (FMABC) from March 2007 to May 2010. The patients fulfilled the inclusion criteria for this study: an indication of in vitro fertilization (IVF) due to the lack of pregnancy 1 year after laparoscopy or fallopian tube damage caused by endometriosis, and the presence of regular ovarian cysts with dense content that were suggestive of endometriomas and smaller than $3 \mathrm{~cm}$ in diameter, on average.

All patients were previously diagnosed with endometriosis by laparoscopy and the degree of the illness was established according to the classification of the American Society for Reproductive Medicine ${ }^{(13)}$. Of the 21 patients, $81 \%(17 / 21)$ had stage IV endometriosis and $19 \%$ (4.21) had stage III endometriosis.

The patients had undergone up to four previous surgical interventions. All were on treatments for assissted reproduction due to the tubo-peritoneal factors which were diagnosed during surgery in $48 \%$ (10/21) of the patients and/or through hysterosalpingography in $52 \%(11 / 21)$ of the patients.

The recurrence of endometriosis was characterized by an image suggestive of an endometriotic cyst measuring at least $3 \mathrm{~cm}$ in average diameter that was found during a transvaginal ultrasound examination. The appearance of a typical ultrasound corresponded to a low-density image with diffuse internal echoes, which is seen in $95 \%$ of the endometriomas, and hyperechoic foci on the wall of multilocular cysts ${ }^{(14)}$.

The classically known long protocol was used in which a GnRH agonist analog and recombinant gonadotropins are administered. Triptorelin at a dose of $3.75 \mathrm{mg}$ or goserelin at a dose of $3.6 \mathrm{mg}$ were used for pituitary suppression in the luteal phase prior to starting ovarian stimulation.

Twenty days after the using the GnRH analog and ultrasound confirmation of pituitary suppression (endometrium with a linear appearance and less than $5 \mathrm{~mm}$ and ovaries without follicles greater than 10 $\mathrm{mm}$ ), the endometriomas were manually aspirated with a needle guided by transvaginal ultrasonography and a $20 \mathrm{~mL}$ syringe. Without removing the needle, an injection of ethanol was made that corresponded to $70 \%$ of the volume of the aspirated endometriotic fluid. The alcohol was left in the cyst cavity for 5 minutes before being aspirated. This procedure was performed under anesthesia using propofol. In all cases, prophylactic antibiotic treatment was given, with $1 \mathrm{~g}$ of azithromycin taken orally the day before the puncture.

One week after the aspiration and alcohol treatment, the patients were reevaluated with transvaginal ultrasonography and the controlled ovarian stimulation was started with recombinant follicle stimulating hormone $(\mathrm{FSH})$ - Follitropin $\left(\right.$ Puregon $\left.^{\circledR}\right)$ if the endometrioma was no longer detected. 
The gonadotropin dose used was $100 \mathrm{U} /$ day in nine patients and $200 \mathrm{U} /$ day in patients who only had one ovary or who were older than 38 years of age $(12 / 21)$. When the largest follicle reached a minimum average diameter of $18 \mathrm{~mm}, 5000 \mathrm{U}$ of urinary hCG $\left(\right.$ Choriomon ${ }^{\circledR}$ ) was administered. The ovarian puncture with follicular aspiration guided by transvaginal ultrasonography was performed 34 to 36 hours after the administration of hCG, and the oocytes were fertilized on the same day with priority for conventional IVF. The intracytoplasmic sperm injection (ICSI) technique was indicated only in the cases involving severe male infertility factors.

The luteal phase was supported with micronized progesterone at a dose of $600 \mathrm{mg} /$ day taken vaginally, which began the day after the puncture. The serum dose of quantitative $\beta$-hCG was measured on the 12th day after the embryonic transfer to diagnosis the pregnancy. After confirming the diagnosis of pregnancy, progesterone continued to be applied at the same dose until the 11th week of pregnancy.

The clinical data of the studied patients were collected only after explaining the objectives of the study and after receiving voluntary and informed consent. The study was approved by the local research ethics committee.

The statistical analysis was performed with SPSS software, version 11.0 (SPSS Inc., Chicago, IL, USA). T-tests were used, and $p$-values of $<0.05$ were considered to be statistically significant.

\section{RESULTS}

Of the 21 patients who were studied, $80.9 \%$ (17/21) had one operation, $9.5 \%(2 / 21)$ had two operations, and $4.7 \%(1 / 21)$ had four operations (Table 1$)$. Six of the patients $(28.6 \%)$ only had one ovary due to prior surgical interventions.

The average age was $33.8 \pm 3.5$ years, the average time of infertility was $4.8 \pm 3.5$ years, and the average body mass index $(\mathrm{BMI})$ was $24.0 \pm 2.5 \mathrm{~kg} / \mathrm{m}^{2}$ (Table 1$)$.

Table 1. Clinical characteristics of the studied patients

\begin{tabular}{lcc}
\hline Characteristics & Mean \pm SD & $\%$ \\
\hline Age (years) & $33.86 \pm 3.56$ & \\
Duration of infertility (years) & $4.85 \pm 3.51$ & \\
BMl $\left(\mathrm{kg} / \mathrm{m}^{2}\right)$ & $24.03 \pm 2.55$ & \\
Number. of prior laparoscopies & $1.33 \pm 0.79$ & \\
Single ovary & & 28.57 \\
Endometrioma & & \\
$\quad$ Unilateral & & \\
$\quad$ Bilateral & & 14.28 \\
$\quad$ Size (cm) (TVUS) & $4.68 \pm 1.42$ & \\
$\quad$ Volume of cyst aspirate $(\mathrm{mL})$ & $52.38 \pm 12.72$ & \\
\hline
\end{tabular}

BMI: body mass index; SD: standard deviation; TVUS: transvaginal ultrasonography
The ultrasound images revealed that the endometriomas initially had an average diameter of $4.7 \pm 1.4 \mathrm{~cm}$ (Figure 1). Eighteen patients had unilateral and three had bilateral endometriomas (Table 1). The endometriomas did not recur after aspiration during the induction of ovulation. Also, there were no episodes of infection or significant bleeding from aspiration of the endometriomas.

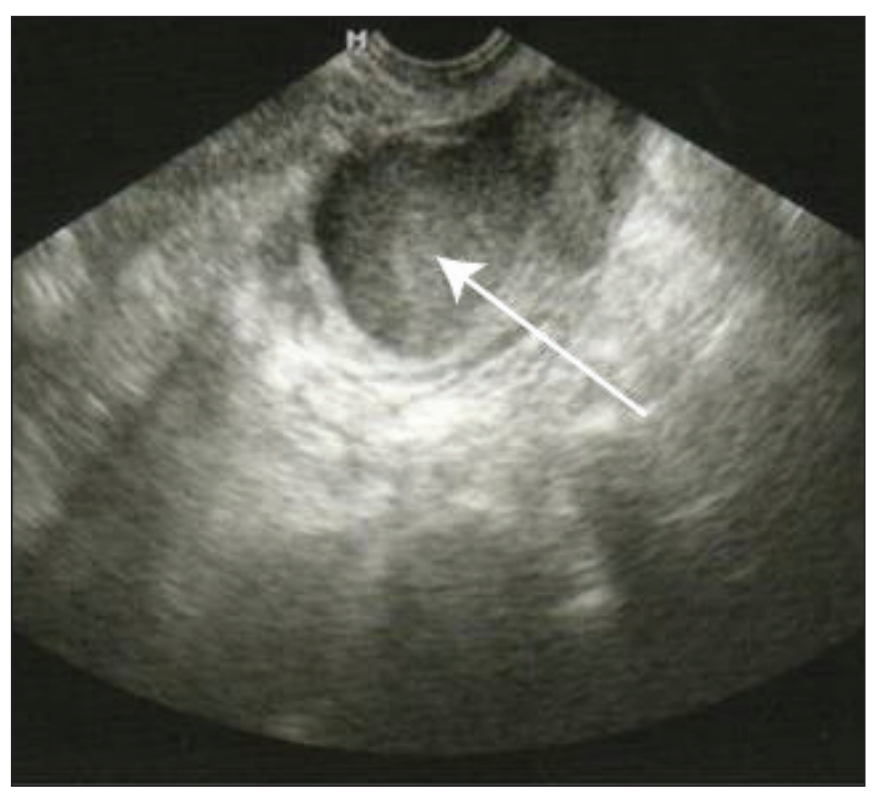

Figure 1. A $3.3 \times 3.8 \mathrm{~cm}$ ovarian cyst with a homogenous and hypoechoic echotexture and diffuse internal echoes with low echogenicity

Oocyte retrieval occurred, on average, $11 \pm 1.7$ days after the induction of ovulation. There was no statistically significant difference between the groups that used $100 \mathrm{U} / \mathrm{d}$ and $200 \mathrm{U} / \mathrm{d}$ recombinant FSH. There were $5.04 \pm 3.78$ follicles and $3.95 \pm 3.30$ oocytes per cycle, which was also not significantly different between the groups (Table 2).

Table 2. Response to gonadotropins

\begin{tabular}{lccc}
\hline Response & $\mathbf{1 0 0} \mathbf{U} /$ day & $\mathbf{2 0 0} \mathbf{U} /$ day & p-value \\
\hline Days of induction & $11 \pm 1.9$ & $11 \pm 1.7$ & 0.8415 \\
Number of follicles & $5.6 \pm 2.4$ & $6.1 \pm 4.1$ & 0.4031 \\
Number of oocytes & $3.6 \pm 1.9$ & $4.5 \pm 4.2$ & 0.2225 \\
\hline
\end{tabular}

Embryos were transferred in $71.43 \%(15 / 21)$ of the patients, and the pregnancy rate after transfer was $20 \%$ (3/15).

\section{DISCUSSION}

There are many treatment options for endometriomas, including observation, drug treatment, and surgery (laparotomy or laparoscopy), which constitute the 
traditional treatments. Aspiration of endometriomas guided by transvaginal ultrasonography, with or without sclerotherapy, has recently been used as a treatment, although several authors have questioned the effectiveness of this method ${ }^{(11,12,15)}$.

Laparoscopic cystectomy to remove ovarian endometriomas is an effective procedure, yet there is no consensus on its use among women with infertility ${ }^{(15)}$. In a recent study performed by Benaglia et al. ${ }^{(16)}$, the authors determined that severe ovarian damage occurring during endometrioma operations was not a rare event. The presence of pelvic adhesions or advanced-stage disease may impede visualization of the anatomical structures, leading to incomplete resection and frequent recurrence ${ }^{(12)}$.

Aspiration guided by transvaginal ultrasonography was proposed in $1991^{(7,8)}$ as an option for patients who refused the operation or if there was a contraindication for surgery. Aspiration is a less invasive, quicker, and less expensive procedure than surgery ${ }^{(17)}$, but it has a greater rate of recurrence and has restrictions on its broader application. Currently, the use of sclerosing substances has been proposed following aspiration with substances including tetracycline ${ }^{(9)}$, methotrexate ${ }^{(10)}$, interleukin $2^{(18)}$, and ethanol ${ }^{(11)}$.

Sclerotherapy was originally used to treat tuberculosis and is currently used by oncologists to treat pleural effusions caused by cancer. The mechanisms involved in the sclerotherapy of ovarian cysts are not completely known, although the lining of epithelial cells appears to be important in the disease process. When there is adequate contact between the sclerosing agent and the cyst wall, a coagulation cascade is activated, inflammatory mediators are produced, and fibrosis of the epithelial cells of the lining occurs, leading to adherence to the cyst wall ${ }^{(12)}$. Sclerotherapy with ethanol is a procedure considered by many authors to be safe and effective, and may be indicated for almost all cases of endometrioma ${ }^{(11,12)}$.

The ultrasound characteristics of the cysts, in addition to the prior histopathological diagnosis of endometriosis, are reassuring for the use of puncture and sclerotherapy.

There is no consensus on the removal of an endometrioma before $\operatorname{IVF}^{(19-21)}$. However, there is evidence that extensive surgeries or repeat surgeries may damage ovarian reserves ${ }^{(22-26)}$, compromising the success of a subsequent $\operatorname{IVF}^{(27)}$. The ovulation rate has repeatedly been shown to be decreased in post-surgical gonads compared to intact gonads ${ }^{(24,28)}$. In cycles of IVF/ICSI, there was a decreased response to controlled ovarian stimulation in the ovaries that underwent the operation ${ }^{(23,25)}$. In addition, the presence of the endometrioma itself may negatively influence ovarian function $^{(16,24)}$ in addition to impeding oocyte aspiration during IVF/ICSI treatment ${ }^{(16)}$.

There are several likely advantages of treating endometriomas by puncture and sclerotherapy in comparison to conventional treatments with resection by video laparoscopy, mainly when there is a recurrence. This technique is less invasive, less expensive, and allows for ovarian and folliculogenesis tissue to be preserved. It may be used before the induction of ovulation in IVF programs. In addition, the use of alcohol appears to significantly reduce the symptoms associated with endometriomas, with a decreased risk of adhesion formation because the procedure is intratumoral ${ }^{(29)}$.

This study demonstrated an effective remission of endometrioma volume after aspiration and the use of alcohol in all reported cases. There were no cases of recurrence seen on ultrasounds performed for the induction of ovulation. It is important to stress that this is a pilot study and a small number of patients were studied. In addition, the study's observation time was only until the end of the in vitro fertilization cycle. It should be noted that due to treatment with GnRH agonist analogs, the pituitary axis was suppressed during this period.

In the present study, the objective was only to evaluate the safety of this procedure and the effects of the intervention on IVF results. The subsequent follow-up of these patients, the recurrence rate of endometriomas, and the ovarian reserves following sclerotherapy should be considered when compared to a control group in a future randomized study.

\section{CONCLUSION}

The use of aspiration and ethanol sclerotherapy for recurring endometriomas did not exhibit any complications and resulted in successful outcomes when performed before IVF. These results should be confirmed through a controlled case study.

\section{REFERENCES}

1. Yanushpolsky EH, Best CL, Jackson KV, Clarke RN, Barbieri RL, Hornstein MD. Effects of endometriomas on ooccyte quality, embryo quality, and pregnancy rates in in vitro fertilization cycles: a prospective, case-controlled study. $J$ Assist Reprod Genet. 1998;15(4):193-7.

2. Al-Azemi M, Bernal AL, Steele J, Gramsbergen I, Barlow D, Kennedy S. Ovarian response to repeated controlled stimulation in in-vitro fertilization cycles in patients with ovarian endometriosis. Hum Reprod. 2000;15(1):72-5.

3. Aboulghar MA, Mansour RT, Serour Gl, Al-Inany HG, Aboulghar MM. The outcome of in vitro fertilization in advanced endometriosis with previous surgery: a case-controlled study. Am J Obstet Gynecol. 2003;188(2):371-5.

4. Somigliana E, Infantino M, Benedetti F, Arnoldi M, Calanna G, Ragni G. The presence of ovarian endometriomas is associated with a reduced responsiveness to gonadotropins. Fertil Steril. 2006;86(1):192-6. 
5. Suzuki T, Izumi S, Matsubayashi H, Awaji H, Yoshikata K, Makino T. Impact of ovarian endometrioma on oocytes and pregnancy outcome in in vitro fertilization. Fertil Steril. 2005;83(4):908-13.

6. Fedele L, Bianchi S, Zanconato G, Berlanda N, Raffaelli R, Fontana E. Laparoscopic excision of recurrent endometriomas: long-term outcome and comparison with primary surgery. Fertil Steril. 2006;85(3):694-9.

7. Dicker D, Goldman JA, Feldberg D, Ashkenazi J, Levy T. Transvaginal ultrasonic needle-guided aspiration of endometriotic cysts before ovulation induction for in vitro fertilization. J In Vitro Fert Embryo Transf. 1991;8(5):286-9.

8. Aboulghar MA, Mansour RT, Serour Gl, Rizk B. Ultrasonic transvaginal aspiration of endometriotic cysts: an optional line of treatment in selected cases of endometriosis. Hum Reprod. 1991;6(10):1408-10.

9. Fisch JD, Sher G. Sclerotherapy with $5 \%$ tetracycline is a simple alternative to potentially complex surgical treatment of ovarian endometriomas before in vitro fertilization. Fertil Steril. 2004;82(2):437-41.

10. Mesogitis S, Antsaklis A, Daskalakis G, Papantoniou N, Michalas S. Combined ultrasonographically guided drainage and methotrexate administration for treatment of endometriotic cysts. Lancet. 2000;355(9210):1160.

11. Noma J, Yoshida N. Efficacy of ethanol sclerotherapy for ovarian endometriomas. Int J Gynaecol Obstet. 2001;72(1):35-9.

12. Hsieh CL, Shiau CS, Lo LM, Hsieh TT, Chang MY. Effectiveness of ultrasoundguided aspiration and sclerotherapy with 95\% ethanol for treatment of recurrent ovarian endometriomas. Fertil Steril. 2009;91 (6):2709-13.

13. Revised American Society for Reproductive Medicine classification of endometriosis: 1996. Fertil Steril. 1997;67(5):817-21.

14. Kinkel K, Chapron C, Balleyguier C, Fritel X, Dubuisson JB, Moreau JF. Magnetic resonance imaging characteristics of deep endometriosis. Hum Reprod. 1999;14(4):1080-6.

15. Jones KD, Sutton CJ. Pregnancy rates following ablative laparoscopic surgery for endometriomas. Hum Reprod. 2002;17(3):782-5.

16. Benaglia L, Somigliana E, Vighi V, Ragni G, Vercellini P, Fedele L. Rate of severe ovarian damage following surgery for endometriomas. Hum Reprod. 2010;25(3):678-82.

17. Zanetta G, Lissoni A, Dalla Valle C, Trio D, Pittelli M, Rangoni G. Ultrasoundguided aspiration of endometriomas: possible applications and limitations. Fertil Steril. 1995;64(4):709-13.
18. Acién P, Quereda FJ, Gómez-Torres MJ, Bermejo R, Gutierrez M. GnRH analogues, transvaginal ultrasound-guided drainage and intracystic injection of recombinant interleukin-2 in the treatment of endometriosis. Gynecol Obstet Invest. 2003;55(2):96-104.

19. Garcia-Velasco JA, Mahutte NG, Corona J, Zúñiga V, Gilés J, Arici A, et al. Removal of endometriomas before in vitro fertilization does not improve fertility outcomes: a matched, case-control study. Fertil Steril. 2004;81(5):1194-7.

20. Gibbons WE. Management of endometriosis in fertility patients. Fertil Steril. 2004;81(5):1204-5.

21. Sharpe-Timms KL, Young SL. Understanding endometriosis is the key to successful therapeutic management. Fertil Steril. 2004;81(5):1201-3.

22. Somigliana E, Vercellini P, Viganó P, Ragni G, Crosignani PG. Should endometriomas be treated before IVF-ICSI cycles? Hum Reprod Update. 2006;12(1):57-64.

23. Somigliana E, Daguati R, Vercellini P, Barbara G, Benaglia L, Crosignani PG. The use and effectiveness of in vitro fertilization in women with endometriosis: the surgeon's perspective. Fertil Steril. 2009;91(5):1775-9.

24. Horikawa T, Nakagawa K, Ohgi S, Kojima R, Nakashima A, Ito M, et al. The frequency of ovulation from the affected ovary decreases following laparoscopic cystectomy in infertile women with unilateral endometrioma during a natural cycle. J Assist Reprod Genet. 2008;25(6):239-44.

25. Tsoumpou I, Kyrgiou M, Gelbaya TA, Nardo LG. The effect of surgical treatment for endometrioma on in vitro fertilization outcomes: a systematic review and meta-analysis. Fertil Steril. 2009;92(1):75-87.

26. Garcia-Velasco JA, Somigliana E. Management of endometriomas in women requiring IVF: to touch or not to touch. Hum Reprod. 2009;24(3):496-501.

27. Vercellini $P$, Somigliana E, Viganò $P$, Abbiati A, Barbara G, Crosignani PG. Surgery for endometriosis-associated infertility: a pragmatic approach. Hum Reprod. 2009;24(2):254-69.

28. Candiani M, Barbieri M, Bottani B, Bertulessi C, Vignali M, Agnoli B, et al. Ovarian recovery after laparoscopic enucleation of ovarian cysts: insights from echographic short-term postsurgical follow-up. J Minim Invasive Gynecol. 2005;12(5):409-14.

29. O'Neill MJ, Rafferty EA, Lee SI, Arellano RS, Gervais DA, Hahn PF, Yoder IC, Mueller PR. Transvaginal interventional procedures: aspiration, biopsy, and catheter drainage. Radiographics. 2001;21(3):657-72. 